\title{
VALIDAÇÃO DO INSTRUMENTO DE AVALIAÇÃO DE ESTILOS PARENTAIS "CAREGIVER'S FEEDING STYLES QUESTIONNAIRE (CFSQ)" PARA A POPULAÇÃO BRASILEIRA \\ Pôster
}

Autores deste trabalho:

Nathalia Moretti Fontanezi: UNIFESP

Rachel HV Machado : PENSI

Priscila Maximino : PENSI

Mauro Fisberg : PENSI

Área do Trabalho: Nutrição

Data da submissão: 29/07/2018 às 05:44

\section{Justificativa}

O estilo parental exerce forte influência sobre o comportamento alimentar na infância, e a sua determinação pode auxiliar no acompanhamento das dificuldades alimentares. Não há atualmente instrumentos de triagem validados para uso na população brasileira.

\section{Objetivo(s)}

Validar o instrumento americano "Caregiver's feeding styles questionnaire" (CFSQ) para pais brasileiros de crianças de 1 a 7 anos de idade.

\section{Método(s)}

O instrumento original foi traduzido para o português e adaptado segundo aspectos culturais, seguido de retro tradução e a aprovação da autora. A amostra foi calculada em $N=190$, segundo preceitos do teste de análise fatorial confirmatória (AFC), pais de crianças de 1 a 7 anos de idade, de ambos os sexos, abordados na sala de espera de um pronto socorro na cidade de São Paulo. O questionário é composto por 19 questões sobre a frequência de comportamentos específicos no momento das refeições da criança (escala Likert), e foi auto respondido pela amostra, possibilitando cálculo de escores de exigência e resposta, que juntos classificam os pais em estilo controlador, responsivo, ausente e indulgente. Também avaliou-se indicadores IMC/I, E/I e P/I (OMS, 2007), a idade e escolaridade dos pais. O estudo foi aprovado pelo CEP (CAAE 59055916.0.0000.5567; sob o registro 1.760.608).

\section{Resultado(s)}

A média da idade das crianças foi de 3,6 anos $\pm 1,4$ com maioria do sexo feminino $(51,1 \%)$, e identificado $34,7 \%$ de excesso de peso nas crianças. A média de idade das mães foi de 34,7 anos $\pm 5,7$ e dos pais 36,8 anos $\pm 6,8$, com nível superior de escolaridade acima de $76,3 \%$. O estilo parental mais frequente foi indulgente $(39,5 \%)$, seguido por responsivo $(28,4 \%)$, controlador $(23,7 \%)$ e negligente $(8,4 \%)$. 0 questionário apresentou consistência interna boa (alfa de Cronbach total $=0,79$ ), com AFC que se adaptou ao modelo proposto $\left(\mathrm{X}^{2} / \mathrm{df}=2,21 ; \mathrm{p}<0,000 ; \mathrm{RMSEA}=\right.$ $0,07)$. 


\section{Conclusão (ões)}

O CFSQ traduzido para a população brasileira mostrou validade e confiabilidade, podendo ser utilizado como ferramenta para identificar os estilos parentais durante a primeira infância. 